\title{
Antiplatelet Therapy Post Coronary Artery Bypass Grafting: A survey of practice at UK Cardiothoracic Units
}

\author{
Yama Shoaib Haqzad*, Alexandra Woods, Mubarak Chaudhry, Mahmoud Loubani \\ From World Society of Cardiothoracic Surgeons 25th Anniversary Congress, Edinburgh \\ Edinburgh, UK. 19-22 September 2015
}

\section{Background/Introduction}

Bleeding complications and perioperative cardiovascular events are strongly influenced by the management of antithrombotic therapy before and after Coronary Artery Bypass Grafting (CABG). Early thrombosis is a major cause of vein graft attrition after CABG1 with occlusion rates ranging between $5-26 \% 2$. There is scarce evidence in dual antiplatelet therapy post elective CABG.

\section{Aims/Objectives}

The primary objective of this survey was to establish the variations in antiplatelet therapy post CABG in all cardiothoracic units across the United Kingdom (UK).

\section{Method}

A comprehensive list of all cardiothoracic units across the UK was obtained from the Society for Cardiothoracic Surgery (SCTS). 41 units were identified in England, Scotland, Wales and Northern Ireland. Questionnaire regarding antiplatelet therapy was developed and administered to the on call cardiothoracic registrars over a 3 day period. Data was analysed using Microsoft Excel.

\section{Results}

All 41 centres responded to the questionnaire. $300 \mathrm{mg}$ Aspirin (ASA) was given Per Rectum 6 hours post CABG in $66 \%$ of the units while surgeon specific variation existed in $24 \%$ of the units and it was not given in $10 \%$ of the units. Post elective CABG, $51 \%$ of the units gave isolated ASA $75 \mathrm{mg}$ for life while variation between consultants within the unit existed in $27 \%$, dual antiplatelet therapy was used in $10 \%$ and varying doses of ASA administered

\footnotetext{
Department of Cardiothoracic Surgery, Castle Hill Hospital, Cottingham,
} HU16 5JQ, UK

\section{and take full advantage of:}

- Convenient online submission

- Thorough peer review

- No space constraints or color figure charges

- Immediate publication on acceptance

- Inclusion in PubMed, CAS, Scopus and Google Scholar

- Research which is freely available for redistribution

Submit your manuscript at 